\title{
Management Support and Strategies Integration in County Governments in Kenya: A Case of County Government of Kirinyaga
}

\author{
Jopsy Weru* Dennis Muchangi David Njoroge \\ School of Business \& Economics, Kirinyaga University, Po Box 143-10300 Kerugoya \\ *E-mail of the corresponding author:wjopsy@gmail.com
}

\begin{abstract}
County Governments are mandated to design development plans which are incorporated in the five-year strategic plans called County Integrated Development Plans. However, many of these programmes are never integrated into the county structures. Even the strategies that are implemented are only implemented through the goodwill of the existing leadership. They are rarely integrated into the County Government structure and systems. The main objective of the study was to establish the influence of management support on strategy integration in County Governments in Kenya. The study's specific objectives were: To establish the influence of strategic leadership, resource allocation, capacity building and employee involvement on strategies integration in county governments in the County government of Kirinyaga. The study is anchored on three main theories which include McKinsey 7S Theory, Upper Echelon Theory and resource-based view theory. A descriptive study design was applied in the study. The target population in this research project was 277 employees in County Government of Kirinyaga. A sample of 164 respondents was selected but only 100 questionnaires were returned. Primary data was collected by use of questionnaires while secondary data was gathered through a review of the county government documents, published journals and articles. The Drop and pick method were used to administer the questionnaires. Descriptive statistics, regression and correlation analysis was conducted to draw conclusions on the findings. The results revealed a strong positive relationship between management support and Strategy Integration in the County as indicated by the coefficient $(\mathrm{r}=0.872)$. The coefficient of determination $\left(\mathrm{r}^{2}=0.76\right)$ revealed that $76 \%$ of the changes in strategy integration can be explained by the changes in management support while $24 \%$ of the changes in management support can be explained by other factors beyond this study. Based on the Study findings, it was concluded that the level of strategy integration in the county government is highly dependent on the level of management support. Based on the research findings, the study recommended that County leadership should be focused on implementing the strategic goals as outlined in the County Integrated Development Plans without other political disruptions. To meet the goals enlisted in the County development plan, it is recommended that the county governments in Kenya should invest on capacity building to enhance the efficiency of their human resources, endeavor to adopt efficient strategic leadership and increase employee involvement in the planning and execution of the county development plan.
\end{abstract}

Key Words: Management Support and Strategies Integration in County governments

DOI: $10.7176 /$ RJFA/11-18-17

Publication date:September $30^{\text {th }} 2020$

\section{Introduction}

Strategy integration is the process of adopting the strategies throughout the organisation and departments on whereby employees ideally become proficient and consistent in their execution of the strategy (Allio, 2015). When strategies are well integrated in the organisation, they become institutionalised and they inform all the operations and activities of every employee in the organisation (Ansoff \& McDonnell, 2015). Implementing even seemingly simple strategies has proven to be challenging. The rate of successfully implemented strategies is less than 50 percent (Elbanna, Andrews \& Pollanen, 2016). Poor implementation rates may be due to the substantial organizational changes required for the initiatives, which may be cognitively, emotionally, physically, and spiritually demanding of employees and organizations (Jooste \& Fourie, 2016).

In India, Kazmi (2018) indicated that there should be a successful framework applied in the Indian context. This is because most of the proposed strategy implementation frameworks cover many of the aspects hitherto neglected in the frameworks suggested by researchers and authors more attuned to the Western context. Two of the major issues in strategy implementation not covered in the existing framework involve leadership role in procedural and project implementation that may be considered as relevant in the Indian context.

In Pakistan, Azhar, Ikram, Rashid and Saqib (2016) observe that leadership has significant impact on strategic 
management process. It helps to determine the vision and mission of the organization. Further, it facilitates the organization to execute effective strategies to achieve that vision. Leadership serves as a link between the soul and the body of an organization. During the strategic management process leadership, performs the various roles such as innovator, strategist, care taker, analyst, guide, organizer, motivator, developer, change enabler or change driver, decision maker, collaborator, risk manager, debtor, and evaluator. In the recipe of strategic management process, the most important ingredients are leader's responsibility, loyalty, power, motivation, awareness, articulacy (clarity), consistency and reliability.

In Slovenia, Cater and Pucko (2010) established that managers mostly rely on planning and organising activities when implementing strategies, while the biggest obstacle to strategy execution is poor leadership. Moreover, there are greater obstacles to strategy execution in the forms of inadequate leadership skills and employees' reluctance to share their knowledge. These have a negative influence on strategy integration and implementation while adapting the organisational structure to the selected strategy.

Palladan (2018) indicates that in Nigeria, the need for strategic management practices in Nigerian public tertiary institutions grew when the organizations shifted from relatively stable environment to environment that is characterized by increasing competition and shortages of resources. For these institutions, adoption of strategic management practices at this moment is very timely. Strategic management practices are needed in an environment where new forms of influence are imaging and where norms and values as well as social utility of organizations is being challenged and redefined. The main challenge in strategic management process is associated with strategy implementation. Strategic leadership, organizational innovativeness and information technology capability influence effective strategy implementation.

In Kenya, the enactment of the Constitution of Kenya, 2010 provided for devolved system of Government which created County Governments under article 176 (Republic of Kenya, 2010). To achieve the objects of devolution, County governments are required to adopt strategic management practices through preparation of County Integrated Development Plans. The overall objective of the strategic plan is to provide a framework for ensuring integrated development across all sectors and regions of the county (Republic of Kenya, 2012). Devolving authority to county government in 2013 was aimed at enhancing local communities' participation in development with the expectation that it would reduce competition over national resources. It was also hoped county government would enable marginalised regions to catch up with the more developed areas, again addressing and reducing historic regional grievances (Abass, Munga \& Were, 2017).

The County Government Act 2012 specifies key plans that each county is expected to generate. These include the County Integrated Development Plan (CIDP), county sectoral plans, county spatial plans, county urban areas and cities plans, and county performance management plans (Republic of Kenya, 2012). These plans are interrelated as they deal with different aspects of development and they are expected to inform annual budgets and plans. The county government consists of a county assembly and a county executive. Every county government is required to decentralize its functions and the provision of its services to the extent that it is efficient and practicable. The county assembly constitutes the legislative organ of government while the county executive is representative of the executive arm of government within the county government.

In implementing County Integrated Development Plans, county governments face a myriad of challenges. The main challenge is limited financing as many counties depend on the national government for financing. This is because most county governments in Kenya have very low capacity to raise their own revenue (Opano, Shisia, Sang \& Josee, 2015). This combined with other human resource challenges in the counties challenge them in their endeavour to execute and integrate their strategic plans and provide services to the respective communities.

Locally, the challenges affecting strategy implementation in counties include financial-related challenges, human resource-related challenges and leadership-related challenges. Yussuf (2016) indicated that challenges affecting strategy implementation in Mandera County government include poor employee involvement, lack of effective leadership, financial limitations and poor communication of the strategy to all employees. Imoleit, Sakwa and Wandera (2017) established that resources are the major factors affecting implementation of the Bungoma County strategic plan followed by leadership, organizational structure, and communication. Hrebiniak (2006) observe that lack of requisite skills and competencies in employees, inadequate financial allocation, lack of leadership commitment and lack of clear communication and feedback processes were key challenges in strategy implementation.

In county governments, top managers (such as governors, deputy governors and county executives) may help to 
overcome implementation challenges by demonstrating support for strategy implementation. Ansoff and McDonnell (2015) established that employees are more involved in strategy implementation when top managers demonstrated support for implementation-related activities.

\subsection{Statement of the Problem.}

County governments are mandated to design development plans which are incorporated in the five-year strategic plans called County Integrated Development Plans. However, many of these plans are poorly or never implemented (Murrey, 2015). Even the strategies that are implemented are only implemented through the goodwill of the existing leadership. They are rarely integrated into the county government structure and systems. According to Ndungu (2018), in the year 2016/2017, 57\% of development projects completed in Kenya were completed late while $86 \%$ of ongoing projects were behind schedule. The poor execution of strategies by county governments has continued to attract research interest in the second term of the county governments of Kenya from 2013.

Several studies have been conducted on the strategic management of county governments. For instance, studies have been conducted in Kisii (Opano et al., 2015), Mandera (Yussuf, 2016), Wajir Abass et al., (2017) and Bungoma (Imoleit et al., 2017) among other counties, regarding strategy implementation. In Kirinyaga County, Kamukunji (2017) established that 56 percent of the residents were of the opinion that the county does not effectively attain its developmental objectives and strategic plans. The findings from these studies indicate that strategy implementation in most of the counties have not been majorly successful. None of these studies examined the role of management support on strategies integration in the county governments. There is therefore, a need for a study to be carried out to investigate the influence of management support on strategies integration in county governments in Kenya.

\subsection{General Objective}

The main objective of the study was to establish the influence of management support on strategies integration in county governments in Kenya.

\section{Literature Review}

This chapter provides a review of literature relating to management support and strategies integration. The chapter contains theoretical framework which provides the theories that the study is anchored on. The chapter also presents the conceptual framework which presents the hypothesized relationship amongst the study variables as well as the research gap that the study seeks to fill.

2.1 Theoretical Framework

\subsubsection{McKinsey 7S Theory}

The McKinsey 7S theory of strategy implementation summarizes the aspects that managers should consider to ensure successful implementation and integration of strategies in the organization (Pearce \& Robinson, 2007). These are the 7s namely strategy, structure, systems, style, staff, superordinate goals and skills (David, 2003). A strategy is a set of actions that you start with and must maintain. Structure is the way people and tasks/work are organized, systems are the processes and information flows that link the organization together, style is the way managers behave, staff is the way an organization develops managers (both current and future), superordinate goals are the longer-term vision, and all that values that shapes the destiny of the organization while skills are the dominant attributes or capabilities that exist in the organization.

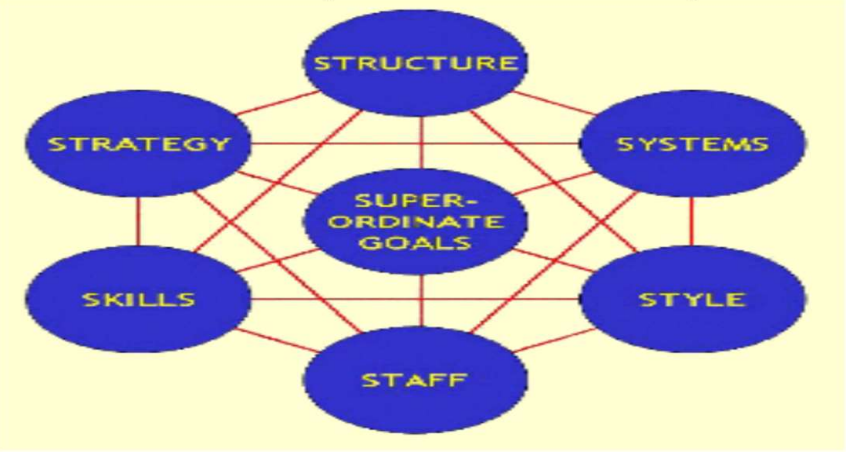

Figure 2.1: The McKinsey 7S Model

Source: Waterman et al. (1980) 
As indicated in Figure 2.1, all these variables are interdependent. Therefore, if the manager fails to pay proper attention to one of them, it can negatively influence the others and hence lead to suboptimal implementation of strategy (Thompson \& Strickland, 1988). The relative importance of each factor will vary over time. The Framework is useful way of checking that one has covered all the bases. This model will be applied in the study to inform how strategic leadership and capacity building can singularly and together influence implementation and integration of strategy in the organization.

\subsubsection{Upper Echelon Theory}

The upper echelon theory proposes that decisions made by executives are coherent with managerial background characteristics (Hambrick \& Mason, 1984) which comprises of the elements of psychological characteristics and observable experiences. Mavhiki (2012) suggested that executive experiences, values and personalities greatly influence their interpretation of the situations they face and in turn affect their choices. The upper echelon theory highlights that executive cognitive base, demographic characteristics, resource utilization, quality of decisions and capabilities influence the strategy choice and corporate performance (Hambrick, 2007).

The effectiveness of strategy execution is triggered by management, monitoring of the process and posing a clear direction of the project. Okioga (2012) argues that, management should be willing to change and accept the fact that the exercise involves learning from lower level to the top-level management of the firm. The role of top-level managers is to attach management bonuses with project success (George \& Desmidt, 2014). Therefore, top management influence the execution of strategic plans.

\subsection{Review of Variables \\ 2.2.1 Strategic Leadership}

Strategic leadership refers to a manager's potential to express a strategic vision for the organization, or a part of the organization, and to motivate and persuade others to acquire that vision (Marginson, 2012). Strategic leadership can also be defined as utilizing strategy in the management of employees. It is the potential to influence organizational members and to execute organizational change. Strategic leaders create organizational structure, allocate resources and express strategic vision. Strategic leaders work in an ambiguous environment on very difficult issues that influence and are influenced by occasions and organizations external to their own.

The main objective of strategic leadership is strategic productivity. Another aim of strategic leadership is to develop an environment in which employees forecast the organization's needs in context of their own job. Strategic leaders encourage the employees in an organization to follow their own ideas through effective communication, mentorship and feedback (Lynch, 2012). Strategic leadership make greater use of reward and incentive system for encouraging productive and quality employees to show much better performance for their organization.

\subsubsection{Capacity Building}

Capacity building entails ensuring that both the leaders and employees understand the strategy and have the knowledge and skills to ensure effective implementation. All employees should understand the vision, mission and mechanics of the strategic plan. Those who will be implementing the strategy need to be trained on effective implementation to enable them to understand the strategies integration mechanics and processes to be put in place. Employees also need to understand the metrics used in performance measurement, when monitoring and evaluation will be conducted and who will participate in performance evaluation.

Marchngton (2015) observes that employees should be provided with an explanation as to why certain decisions were made and an opportunity to be involved in decisions that are in their domain. As far as strategies integration is concerned, training should be provided to both the managers and employees who are actively involved in strategic implementation. Williams (2012) outlines that training is essential for all employees to develop the requisite skills for effective strategic planning, execution monitoring and performance measurement. Secondly capacity building develops a sense of commitment and ownership in the employees. In this study, indicators of capacity building needs assessment, training and education.

\subsection{Research Gap}

The study by Imbali, Muturi, and Abuga (2016) on factors influencing strategy implementation in the tourism industry, conducted at Maasai Mara National Park in Kenya, revealed that support by top management as well as employee empowerment were the most influential in strategy implementation. However, the study considered only two variables of this study, and the study is on the tourism industry and not county governments. 
Further, Mumenya, Mokaya, and Kihara (2014) studied the role of leadership in effective strategy implementation in the manufacturing industry in their case study of Bidco Oil Refineries in Nakuru County, Kenya. The study established that organizational leadership and capacity building were the most important factors influencing effective strategy implementation. Ng'ang'a and Ombui (2013) in their study on, factors influencing implementation of strategic plans in public secondary schools in Lari District, Kiambu County found that leadership was key in the execution of strategic plans followed by resource allocation, communication and organization structure. These studies failed to consider employee empowerment which is included in the current study. The literature reviewed clearly indicates a gap on the role management support plays in the success of strategy integration in the county governments. This study sought to bridge that gap by researching the how management support influenced Strategy Integration in the County Governments.

\section{Research Methodology}

This study used a descriptive study design. In this study, a descriptive survey was conducted to establish in detail the state of management support in strategy integration at the County Government of Kirinyaga. This design was to enable the study to get details and also to relate management support constructs with integration of strategic planning. The target population in this research was all the 277 employees in the County Government Kirinyaga. The study used both stratified and systematic random sampling technique to select an proportionate sample from each department. The sample for the study was computed using the formula provided by Yamane (1967) as quoted by Saunders, Lewis and Thornhill (2015). The formula was as follows;

$$
\begin{aligned}
& n=\frac{N}{1+N e^{2}} \\
& \mathrm{n}=277 / 1+277(0.05)^{2} \\
& =164
\end{aligned}
$$

Table 3.1 Operational Definition of Variables

\begin{tabular}{lll}
\hline Variable & Measures & Level of measurement \\
\hline & & Ordinal (Likert scale questions) \\
& - & \\
Strategic Leadership & - Staff Mentorship & \\
& - & Edherence to CIDP \\
& & making
\end{tabular}

Ordinal (Likert scale questions)

- Needs assessment

- Training

Capacity building
- Performance management

- Attendance of seminars and workshops 
analysis through a software. After collection of questionnaires from the study site, the questionnaires were sorted to establish whether they were correctly filled. Only questionnaires that were correctly filled were considered for the analysis. Data coding was done, and the raw data was entered into Statistical Package for the Social Sciences (SPSS) which generated the required statistics. Descriptive statistics including frequency distribution, percentages, means and standard deviations were used for analysis. This was to enable the study establish the extent of management support and strategy integration in Kirinyaga County Government.

The study applied linear regression for the analysis to assess the relationship between the variables. The independent variables used in the linear regression included strategic leadership, and capacity building. The dependent variable was strategy integration in Kirinyaga County Government. Test of significance in the regression model was conducted on 5\% significance level. The researcher chooses to use this model as the data was continuous, free from multicollinearity and autocorrection.

The following regression multiple equation was used

$\mathbf{Y}=\boldsymbol{\beta}_{0}+\beta 1 \mathbf{X}_{1}+\beta 2 X_{2}$

Where:

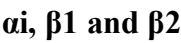

$\mathbf{Y}=$ Strategies Integration in the County

$\mathbf{X}_{\mathbf{1}}=$ Strategic leadership

$\mathbf{X}_{2}=$ Capacity building

\section{Results and discussion}

The main objective of the study was to establish the influence of management support on strategy integration in the county governments in Kenya. This chapter presents the results of data analysis as well as the discussion of key findings of the research basing on the specific objectives which were strategic integration and capacity building. Descriptive, Regression and Correlation findings were used to show the relationship between the variables and answer the research question.

\subsection{Descriptive Analysis}

The first objective was to establish the influence of strategic leadership on strategies integration in county governments in Kenya. Strategic leadership in the county government was measured in terms of idea articulation, staff mentorship, loyalty of the top leaders to the County Integrated development plan, involvement of county employees in decision making, delegation of authority, motivation to achieve County vision and the relationship between top leaders and the county employees.

On the question whether the County leadership effectively articulates ideas regarding the County Integrated Development Plans (CIDP), the mean response was 1.57 implying that the majority of the respondents agreed that the county executives clearly articulate ideas on CIDP. The results also indicated that majority of the respondents strongly agreed that the county leadership of Kirinyaga have managed to mentor key staffs who act as the champions to the CIDP as indicated by the mean response of 1.36. Majority of the respondents strongly agreed to the question whether the county leadership demonstrate loyalty to the CIDP as revealed by the mean response of 1.53 .

The results also revealed that majority of the respondents strongly agreed that the County leadership appreciates the views of the county employees and involves them in decision making as indicated by the mean response of 1.40. The lowest standard deviation was 0.386 while the highest was 0.658 . This implies that there was no much variance in the responses given by the respondents. 
Table 4.1 Descriptive findings on Strategic Leadership

\begin{tabular}{llll}
\hline Operationalized Items & Valid (N) & Mean & St \\
\hline The leadership in the county 100 & 1.57 & .573 \\
government effectively articulates & & \\
the idea about the County & & \\
integrated development plan &
\end{tabular}

Standard Deviation

573

County leaders have managed to integrated development plan

Top leaders in the county demonstrate their loyalty to the County integrated development plan by their words and actions

Leaders in the county understand the feelings and views of the county employees and make decisions after considering them
100

\subsection{Capacity Building}

The second objective was to examine the influence of capacity building on strategies integration in county governments in Kenya. The descriptive statistics on Table 4.11 revealed that majority of the respondents agreed that the County government of Kirinyaga conducts needs assessment to establish the training needs for its employee as implied by the mean response of 1.62. The mean of 1.76 indicated that majority of the respondents also agreed that the county government regularly trains its employee in order to enhance their capacity to carry out their responsibilities. The respondents agreed that the county also has an effective system for performance management. The mean response of 1.66 also indicated that the respondents agreed that the county government allocates sufficient resources to cater for the development of the employee.

As indicated in the results below, majority of the respondents strongly agreed that the county officials often attend seminars, trainings and other forms of workshops in order to enhance their capacity to deliver. The mean of 1.37 also indicated that the county government is also committed to ensuring that the implementation of the strategic plans is also supported through capacity building activities. The lowest standard deviation for this variable was 0.485 while the highest standard deviation for this question was 0.794 . This implied that there was no much variance in the responses given by the respondents. The results can be shown in a table as follows: 
Table 4.2 Descriptive findings on Capacity building

\begin{tabular}{lcc}
\hline Operationalized Item & Mean & Standard deviation \\
\hline $\begin{array}{l}\text { The county government of Kirinyaga } \\
\text { conducts a needs assessment to establish the } \\
\text { employee training needs }\end{array}$ & 1.62 & .708 \\
The county government regularly trains \\
employee to enhance their capacity to \\
deliver in their responsibilities
\end{tabular}

\subsection{Correlation Findings}

Correlation is a statistical tool that is used by a researcher to examine the relationship that exists between or among various variables. According to Wanyama (2012), correlational findings also help the researcher to identify the varying characteristics of each variable from each other. This study used Karl Pearson's coefficient correlation (r) to test for any relationship among the variables. The coefficient correlation range was from -1 to +1 with a 0 representing no linear association between the variables under study, -1 indicating a negative relationship between the variables under study while +1 indicating a positive association between the variables. The relationship is said to be strong when $r$ is greater than 0.5 and weak when $r$ is less than 0.5 .

The correlation findings as shown in table 4.15 below revealed that there was a strong relationship between strategic leadership and strategic integration in the county as indicated by $(r=0.575)$. It was also revealed that there was a strong relationship between capacity building and strategy integration in the county as indicated by the $(\mathrm{r}=0.721)$. The results are shown in Table 4.3 as follows:

Table 4.3 Correlation findings

\begin{tabular}{|c|c|c|c|c|}
\hline & & $\begin{array}{c}\text { Strategic } \\
\text { Integration in } \\
\text { the County }\end{array}$ & $\begin{array}{l}\text { Capacity } \\
\text { Building }\end{array}$ & $\begin{array}{c}\text { Strategic } \\
\text { Leadership }\end{array}$ \\
\hline \multirow{3}{*}{$\begin{array}{l}\text { Strategic Integration in the } \\
\text { County }\end{array}$} & Pearson Correlation & 1 & $.721^{* *}$ & $.575^{* *}$ \\
\hline & Sig. (2-tailed) & & .000 & .000 \\
\hline & $\mathrm{N}$ & 100 & 100 & 100 \\
\hline \multirow[t]{4}{*}{ Capacity Building } & Pearson Correlation & $.721^{* *}$ & 1 & $.577^{* *}$ \\
\hline & Sig. (2-tailed) & .000 & & .000 \\
\hline & $\mathrm{N}$ & 100 & 100 & 100 \\
\hline & $\mathrm{N}$ & 100 & 100 & 100 \\
\hline \multirow[t]{3}{*}{ Strategic Leadership } & Pearson Correlation & $.575^{* *}$ & $.577^{* *}$ & 1 \\
\hline & Sig. (2-tailed) & .000 & .000 & \\
\hline & $\mathrm{N}$ & 100 & 100 & 100 \\
\hline
\end{tabular}

4.4 Regression Findings

The descriptive statistics and correlation analysis provided a proper insight on the relationship between the variables. The regression tool however, helps the researcher to understand the direction of the relationship among 
the variables. To explore the effect of individual independent variable towards the dependent variable, the researcher run a regression for each determinant. Later on, the researcher collectively analysed all the independent variables to find out their effect on the dependent variable. The regression model was however, tested for its fitness before use. The independence of the variables was tested using Durbin Watson coefficients.

Table 4.4 Test of Independence

Model Summary

\begin{tabular}{|c|c|c|c|c|c|}
\hline Model & $\mathrm{R}$ & R Square & Adjusted R Square & $\begin{array}{l}\text { Std. Error of the } \\
\text { Estimate }\end{array}$ & Durbin-Watson \\
\hline 1 & $.872^{\mathrm{a}}$ & .760 & .748 & .32299 & 1.694 \\
\hline \multicolumn{6}{|c|}{ a. Predictors: (Constant), Strategic Leadership, Capacity Building } \\
\hline
\end{tabular}

According to Singh and Masuku (2014), linear regression assumes that there is no interdependence of variables and therefore the autocorrelation is also minimal. To test the independence of the variables, Durbin Watson (d) test was performed. The $\mathrm{d}$ value was $(\mathrm{d}=1.694)$ indicating that there was no autocorrelation among the variables used as shown in table 4.16. According to Genest and Remillard (2004), there is no autocorrelation of data when the dvalue lies between 1.5 and 2.5 and therefore, the variables were independent. These results indicated that the regression model was fit to be used in analyzing the data.

Table 4.5 Regression Findings on Strategic leadership

Model Summary

\begin{tabular}{lcccc} 
Model & $\mathrm{R}$ & R Square & Adjusted R Square & Std. Error of the Estimate \\
1 & $.575^{\mathrm{a}}$ & .330 & .322 & .53000 \\
a. Predictors: (Constant), Strategic Leadership & & \\
\hline
\end{tabular}

The first objective was to establish the influence of strategic leadership on strategies integration in the county governments in Kenya. The regression results revealed that there was a positive strong relationship between strategic leadership in the county and the Integration of strategies to the development plans. As indicated in the Table 4.1, Strategic leadership explains about 33\% of the strategies Integration in Kirinyaga County. The remaining $67 \%$ can be explained by other factors.

Table 4.6 Anova Table on Strategic Leadership

ANOVA $^{\mathrm{a}}$

\begin{tabular}{llrrrrr} 
Model & & Sum of Squares & Df & Mean Square & F & Sig. \\
\hline 1 & Regression & 12.181 & 1 & 12.181 & 43.362 & $.000^{\mathrm{b}}$ \\
& Residual & 24.719 & 88 & .281 & &
\end{tabular}

a. Dependent Variable: Strategic Integration In the County

b. Predictors: (Constant), strategic Leadership

In order to test the significance of the model, a regression was run to assess whether strategic leadership can be considered for the purpose of predicting changes in the integration of the development plans in Kirinyaga County. The regression results indicated that the model was significant $(\mathrm{F}(1,88)=43.362, \mathrm{P}<0.000)$ at $5 \%$ level of significance. These results can be presented in a Table 4.18 above. 


\section{Table 4.7 Regression Findings on capacity building}

The second objective was to examine the influence of capacity building on Strategy integration in the County government. The table below presents regression findings on capacity buildings.

Model Summary

\begin{tabular}{lcccc} 
Model & $\mathrm{R}$ & $\mathrm{R}$ Square & Adjusted R Square & Std. Error of the Estimate \\
\hline 1 & $.721^{\mathrm{a}}$ & .520 & .514 & .44870 \\
a. Predictors: (Constant), Capacity Building & &
\end{tabular}

The regression results revealed a strong positive relationship between capacity building and strategies integration in the development plans of Kirinyaga County $(\mathrm{r}=0.721)$. The $\mathrm{R}^{2}$ indicated that capacity building explained $52 \%$ of the changes in strategy integration while the rest can be explained by other factors. The results can be illustrated in a table as shown above.

Table 4.8 ANOVA table on Capacity building

Table 4.8 below presents the regression findings on capacity building

ANOVA $^{\mathrm{a}}$

\begin{tabular}{|c|c|c|c|c|c|c|}
\hline Model & & Sum of Squares & Df & Mean Square & $\mathrm{F}$ & Sig. \\
\hline \multirow[t]{3}{*}{1} & Regression & 19.183 & 1 & 19.183 & \multirow[t]{3}{*}{95.280} & \multirow[t]{3}{*}{$.000^{\mathrm{b}}$} \\
\hline & Residual & 17.717 & 88 & 201 & & \\
\hline & Total & 36.900 & 89 & & & \\
\hline \multicolumn{7}{|c|}{ a. Dependent Variable: Strategic Integration In the County } \\
\hline \multicolumn{7}{|c|}{ b. Predictors: (Constant), Capacity Building } \\
\hline
\end{tabular}

A regression was carried out to examine the influence of capacity building on Strategic integration in Kirinyaga County. The variable was found to be significant $(\mathrm{F}(1,88)=19.183, \mathrm{P}<0.000)$ at $95 \%$ confidence level. The results are presented in the ANOVA table above.

4.5 Discussion of Findings

4.5.1 Strategic Leadership and Strategies Integration in the County

The regression findings revealed that Strategic leadership has a strong positive relationship with strategies integration in the County Government of Kirinyaga as revealed by $\mathrm{r}(0.575)$. The relationship is also significant as indicated by $(\mathrm{p}=000)$. The findings also indicated that strategic leadership explains $33 \%$ of the changes in strategic integration in the County. These results implied that the strategic leadership of Kirinyaga County is efficient. The descriptive statistics also indicated that majority of the respondents were of the opinion that the strategic leadership of Kirinyaga County is generally efficient and effective as revealed by the mean response where the least mean was 1.18 while the highest mean was 1.57 implying that majority of the respondents agreed that the leadership of Kirinyaga County was effective. The correlation findings $(r=0.575)$ revealed that Strategic leadership plays a vital role in the institutionalization of organization's long-term plan and in the facilitation of a continuous alignment of business strategies within the organizational culture, processes, employees and the ever-changing business environment. These results were consistent with the findings of Lynch, (2012) who argued that strategic leaders encourage the employees in an organization to follow their own ideas through effective communication, mentorship and feedback.

\subsubsection{Discussion Findings for Capacity Building and Strategies Integration}

The regression results revealed a strong positive relationship between capacity building and Strategies Integration in the development plans of Kirinyaga County as revealed by the $r$-coefficient $(r=0.721)$. The $R^{2}$ indicated that capacity building can explain about $52 \%$ of the changes in Strategy Integration while the rest can be explained by other factors. The results implied that the County Government of Kirinyaga is doing well in terms of capacity building and this has played a key role in influencing the integration of strategies in the developmental plans for the County.

Through capacity building, the County employees and leaders are able to understand the strategies and have the knowledge and the required skills to ensure effective implementation of the development plans. Williams (2012) 
outlines that training is essential for all employees to develop the requisite skills for effective strategic planning, execution monitoring and performance measurement. Investing in capacity building develops a sense of commitment and ownership in the employees.

\section{Conclusion}

The main purpose of the study was to be to establish the influence of management support on strategies integration in county governments in Kenya. Specifically, the study aimed at determining whether strategic leadership and capacity building have an influence on strategies integration in Kirinyaga County. This chapter presents the study summary, the conclusions drawn from the study findings and the recommendations made.

The first objective of the study was to establish the influence of strategic leadership on strategies integration in county governments in Kenya. The results revealed a significant positive relationship between Strategic leadership and Strategies Integration. Basing on the result findings (by $\mathrm{r}=0.575$ ), the study concluded that Strategic leadership activities influence Strategy integration process of County governments in Kenya.

The second objective of the study was to examine the influence of capacity building on strategies integration in county governments in Kenya. The results $((\mathrm{r}=0.721)$ revealed a positive significant relationship between Capacity building and Strategy Integration. Based on these findings, it was concluded that the County Government of Kirinyaga has invested sufficiently on Capacity building and has a great influence on Strategy integration in Kirinyaga County. The study revealed that both strategic leadership and capacity building were significant determinants of effective strategy integration in the County governments. The study was in agreement with the results of other scholars who also found a strong positive relationship between strategic leadership and capacity building on strategy integration.

Based on the above findings, the study makes the following recommendations:

The study revealed that strategic leadership has a strong positive relationship on Strategies Integration in the County. This study therefore, observes that the potential of management to express deliberate vision for the organization, and to motivate and persuade others to acquire that vision is key in enhancing strategy implementation. It is therefore recommended that County leadership should be focused on implementing the strategic goals as outlined in the County Integrated Development Plans without other political disruptions.

Secondly, the study found out a strong positive relationship between capacity building and Strategies Integration. The study therefore recommends that the county governments in Kenya should invest on capacity building to enhance the efficiency of their human resources.

\section{References}

Abass, M. K., Munga, J. \& Were, E. (2017). The relationship between strategy implementation and performance in county governments of Kenya: A case study of Wajir County government. International Academic Journal of Human Resource and Business Administration, 2(3), 381-401.

Allio, M.K. (2015). A Short, Practical Guide to Implementing Strategy. Journal of Business Strategy, $26,12-21$.

Ansoff, H. E. \&McDonnell, E. (2015). Implanting Strategic Management. New Jersey: Prentice Hall.

Bourgeois, L. J. \& Brodwin, D. R. (2014): Strategic Implementation: Five Approaches to an Elusive Phenomenon. Strategic Management Journal, 5(3) 241- 264.

Kamukunji, J. K. (2017). Strategic planning practices and performance of Kirinyaga county Government in Kenya. Review of International Business and Strategy, 27(2), 84 - 96.

Lynch, R. (2012). Strategic Management, (6th ed). Cape Town: Pearson Education Limited.

Marginson, D. E. W. (2012). Management control systems and their effects on strategy formation at middle management levels: Evidence from a UK organization. Strategic Management Journal, 23, 1019-31.

Mason,J.H., Hyman, J. \& Mason, B. (1995). Managing Employee Involvement and Participation. Sage: London.

Ng'ang'a, W. J., \& Ombui, K. (2013). Factors Influencing Implementation of Strategic Plans in Public Secondary Schools in Lari District, Kiambu County; International Journal of Science and Research (IJSR), 2(11), 2319-7064.

Okioga, C. K. (2012). Strategies Which Are Key to the Success of the Corporate Institution in Kenya. A Case of Selected Corporate Institutions in Kenya. European Journal of Business and Management, 4(15), 31 43.

Opano, J. O., Shisia, A., Sang, W. \& Josee, V. M. (2015) Strategic Planning and Implementation practices at the Kisii County Government in Kenya. International Journal of Economics, Commerce and Management, $3(6), 13-47$. 
Saunders, M., Lewis, P. \& Thornhill, A. (2015). Research Methods for Business Students (7th ed.). London: Pearson. 